\title{
AS REPRESENTAÇÕES DA VIOLÊNCIA NOS EPISÓDIOS ESTUDANTIS DE 1968
}

\section{Maria Ribeiro do Valle ${ }^{l}$}

\begin{abstract}
Resumo
0 presente artigo trata dos principais acontecimentos que envolvem o Movimento Estudantil durante o ano de 1968 no Brasil, criando uma rede que reúne seus interlocutores - 0 governo, a imprensa, a população - em um "diálogo" conturbado. Ele se divide em quatro momentos fundamentais: a morte de Edson Luís (28/03/68) como o marco para a passagem do movimento estudantil ao enfrentamento; a sexta-feira sangrenta (em 21/06/68) e a passeata dos cem mil (em 26/06/68); a guerra da Maria Antônia (em 02/10/68); e $030^{\circ}$ Congresso da UNE, que tem início em 11/10/68. 0 fio condutor para a análise destes episódios são as diversas representações da violência que aí emergem.

Palavras-chaves: Movimento Estudantil. Ditadura Militar. 1968. Violência. Imprensa.

Abstract

The present article discusses the principle events that involved the Student Movement during 1968 in Brazil, creating a network that brings together its interlocutors - the government, the press, the population - in a tumultuous "dialogue." It is divided into four fundamental moments: the death of Edson Luís (03/28/68) as the starting point for the shift of the student movement toward confrontation;
\end{abstract}

${ }^{1}$ Professora do Departamento de Sociologia da Unesp de Araraquara. 
bloody Friday (on 06/21/68) and the march of the 100,000 (06/28/68); the war of Maria Anônia (on 10/02/68); and the 30th Congress of the UNE, which begins on $10 / 11 / 68$. The unifying theme in the analysis of these episodes are the diverse representations of violence that emerge.

Keywords: Student Movement. Military Dictatorship. 1968. Violence. Press.

\section{ApresentaÇÃo}

$\mathrm{N}$

o combate entre o Movimento Estudantil (ME) e a ditadura militar, em 1968, a violência emerge no discurso e na ação, ganha visibilidade na imprensa e interfere no posicionamento diverso dos atores que, num mesmo movimento, repercute no desenrolar dos acontecimentos deste ano ímpar. A polêmica questão da violência no interior do Movimento Estudantil passará por redefinições, ao longo do ano, que não podem ser desconectadas do processo político mais amplo e do posicionamento da grande imprensa que repercute no movimento oscilatório da população. As diversas representações da violência, bem como a sua própria dinâmica imprevisível, contribuem para o desfecho do "diálogo" entre o ME e o governo Costa e Silva - o sonho revolucionário contra 0 fechamento do regime.

\section{A Morte de Edson Luís}

A morte de Edson Luís no dia 28 de março permite-nos iniciar o acompanhamento do percurso da violência no ano de 68, quando ocorre a opção do Movimento Estudantil por lançar mão da mesma arma que vinha então sendo utilizada pelo governo. Edson Luís assassinado pela PM: estudante secundarista, pobre, trabalhador, recém-chegado ao Rio de Janeiro. Não traz, portanto, adjetivos como líder subversivo, comunista, agitador, tão caros às buscas militares. Morre indefeso enquanto faz a sua refeição no Calabouço - restaurante universitário no qual auxiliava na limpeza para poder prosseguir em seus estudos. 0 primeiro assassinato explícito da ditadura, como enfatizam os estudantes. A violência policial explode contra um inocente levando setores da população de vários estados à indignação. A morte de Edson Luís é, assim, o primeiro incidente a sensibilizar a opinião pública para a luta estudantil. Para os estudantes, o extraordinário comparecimento da população no enterro de Edson Luís, além de expressar a 
revolta contra o seu assassinato, significa a repulsa às contradições do sistema vigente, injusto (O METROPOLITANO, 1968, p.6).

0 governo utiliza-se do argumento legal-policial para justificar a invasão ao Calabouço, ou seja, caracteriza o protesto estudantil como ilegal por ocorrer sem a autorização dos órgãos responsáveis pela segurança pública. A PM apenas reage ao ataque dos estudantes, segundo os relatos das autoridades envolvidas no incidente. A ação da polícia é sustentada pelo discurso governamental da manutenção da ordem ameaçada por subversivos. E também pelo fato de se encontrarem os estudantes em maioria e portando número superior de armas. Dessa forma, a agressividade e a violência passam a ser atribuídas aos estudantes, isentando de responsabilidade a PM e, conseqüentemente, o governo. Apenas nos relatos militares e governamentais encontramos alusão ao porte de armas pelos estudantes neste episódio. Notamos, assim, a tentativa do governo de inverter a situação descrita pelos estudantes, pois seus argumentos de revide à invasão policial são lidos como agressão. A evidência da violência policial leva a população à oposição ao regime, ou seja, o tiro sai pela culatra, o governo acaba agindo contra si mesmo (VALLE, 1999, p.67).

A grande imprensa consultada analisa os fatos enquanto conflitos violentos entre a polícia e os estudantes. Embora tanto a revista Visão quanto o Correio da $\operatorname{Manhã~}(C M)$ - diário carioca - condenem a presença da polícia nas manifestações estudantis, acusando-a de gerar violência, podemos perceber que são bastante distintas as suas análises. A indignação frente à ação policial, que atira contra jovens indefesos, é estampada nas matérias do $C M$ que atribui a violência não apenas à PM, mas também às autoridades civis e militares responsáveis pela sua atuação (CM, 29/03/68, p.12). Já Visão responsabiliza tanto a polícia - que age com autonomia -, quanto os estudantes pelo uso da violência, isentando, assim, de co-responsabilidade o governo (VISÃO, 12/04/68, p.21).

Para o $C M$, a intervenção policial impede um protesto justo e legítimo, rompendo com a democracia (CM, 29/03/68, p.12). Em contrapartida, Visão argumenta que a violência da PM acaba dando ao ME a bandeira que lhe falta para assumir a luta política contra o governo, comprometendo a tranqüilidade nacional. Visão justifica, então, a necessidade da intervenção do governo para a manutenção da ordem frente à opção dos estudantes pela violência e ao despreparo da polícia (VISÃO, 12/04/68, p.21).

0 distinto posicionamento destes dois veículos de comunicação mostra a emergência de uma polarização da imprensa frente ao combate que começa a 
ser travado entre o Movimento Estudantil e o governo. 0 CM veicula uma versão favorável ao ME, fato que podemos notar também pela grande cobertura dada aos seus protestos e às suas falas (CM, 29/03/68, p.12). Enquanto, por outro lado, torna-se cada vez mais evidente a ênfase de Visão à versão do governo bem como a proximidade de suas argumentações, insistindo em divulgar a importância do papel do Estado na manutenção da ordem e na garantia da legalidade. Visão também, ao apontar para a autonomia da PM, isenta de responsabilidade 0 governo por sua atuação (VISÃO, 26/04/68, p.23).

CM relata que, no episódio do Calabouço, a PM recebe ordens previamente para reprimir, derrubando o argumento governamental de que esta atua apenas contra 0 ataque dos estudantes. Estes últimos, segundo o jornal em questão, durante a passeata - que considera legítima - praticam a violência apenas em resposta à repressão, invertendo, assim, o argumento governamental, pois são os estudantes que agem em legítima defesa. CM, por outro lado, afirma que tais atitudes da polícia significam a violação do Estado de direito, pois suprime o direito de manifestação da sociedade. 0 CM atrela a atuação da PM e das Forças Armadas às ordens recebidas das autoridades que estão em seu comando, apontando para a co-responsabilidade dos governadores, dos ministros militares e do Presidente da República (CM, 03/04/68, p.10. "Militares querem ato institucional").

\section{A Sexta-Feira Sangrenta e a Passeata DOS CEM MIL}

Em junho de 1968, as manifestações estudantis tomam novamente as ruas, sendo vinculadas pelo governo às manifestações estudantis que eclodem em diversos países, a partir de maio, fortalecendo a divulgação de um plano internacional de subversão e da construção do inimigo externo. Nesta conjuntura, o "diálogo" é proposto pelos mais diversos setores militares e governamentais como contenção das agitações estudantis: por meio dele buscam mostrar a sua disposição para atender as questões estritamente educacionais, isolando a massa dos autênticos estudantes das lideranças subversivas. Mantém, ao mesmo tempo, sua atitude de repressão às manifestações de rua. Por outro lado, a defesa do "diálogo" - sem unanimidade no interior do $\mathrm{ME}$ - faz parte da tática de desmascarar o caráter violento do governo. Tática que busca chegar ao enfrentamento com as forças da repressão (VALLE, 1999, p. 124-5). 
0 CM defende o "diálogo", não como uma preparação para o enfrentamento, mas como uma medida democrática para resolver as questões estudantis. Contudo, condena radicalmente a repressão policial aos protestos de junho e as risíveis fantasias do governo frente ao plano de agitação operária. Afirmando que os estudantes são poder desarmado, critica a argumentação governamental em torno da presença de infiltradores comunistas no ME.

Nas vésperas da Sexta-Feira Sangrenta, os estudantes protestam contra a falta de verbas, os acordos entre o Ministério da Educação e Cultura e a United States Agency for Internacional Development - MEC-USAID e a PEG - Política Educacional do Governo -, no pátio do MEC sendo violentamente reprimidos pela PM. Na quinta-feira, reúnem-se em assembléia na Praia Vermelha para discutir os resultados do movimento contra a PEG (COELHO, 1990, p. 52-3). 0 cerco policial montado em frente à universidade carioca - sede desta assembléia - terá um trágico desfecho. Cerca de 400 alunos são arrastados para o estádio do Botafogo, sendo vítimas da violência policial.

No dia seguinte, no episódio conhecido como Sexta-Feira Sangrenta (21/06/1968), os estudantes voltam ao pátio do MEC onde são recebidos novamente pela intensa repressão policial. De lá, partem em passeata para denunciar a violência da PM, que por sua vez lança-se sobre a população indiscriminadamente. 0 saldo é de 28 mortos, dentre os quais um policial - morto por um objeto lançado de um dos prédios. 0 dado novo então é que, diante da fúria policial, a população carioca parte para o enfrentamento, revidando à violência indiscriminada da PM nas ruas (VENTURA, 1988, p. 130).

No episódio da morte de Edson Luís, a solidariedade da população aos estudantes, apesar de um quebra-quebra no centro da cidade, não demonstra toda a sua disposição de luta como agora. 0 clima é de guerra. $C M$ diz que a população revida em razão da violência que parte da PM atingindo indiscriminadamente crianças, estudantes, adultos e velhos. Durante o conflito, que ganha enorme proporção, torna-se difícil distinguir agressores de agredidos. 0 governo responsabiliza a imprensa pela dimensão dos conflitos, pois a população revoltase diante das cenas de violência dos dias anteriores, estampadas nas primeiras páginas dos jornais. Os estudantes, por sua vez, agradecem o apoio da população e da imprensa que os apóia, participando de suas manifestações de rua (VALLE, 1999, p.125).

0 diálogo sangrento ocupa as ruas. 0 descrédito em relação ao diálogo está presente na grande imprensa consultada. Os diferentes olhares sobre o mesmo 
episódio passam a coincidir: o "diálogo é a violência”. Afinal, quem é o inimigo? No discurso do governo, o movimento geral de subversão e, agora também, a grande imprensa que, ao dar visibilidade às cenas de guerra, torna-se responsável pela proporção atingida pelos acontecimentos. 0 poder da imagem é inquestionável: a partir das fotos publicadas pelos jornais, o conflito aparece. A população também toma partido, lutando nas ruas contra as forças repressivas (VALLE, 1999, p.125-6).

No olhar dos estudantes, a adesão popular parece esperada pela PM, que age como se estivesse diante de uma guerrilha urbana organizada (SIRKIS, 1980, p. 87). 0 plano geral de subversão anunciado pelo governo parece tomar as ruas. 0 relatório do SNI - Sistema Nacional de Informações - sustenta esta hipótese ao enfatizar a perfeição do esquema das táticas utilizadas pelos estudantes, devido à sua semelhança com as operações militares e à presença de comunistas notórios e líderes cassados na sexta-feira. 0 comandante do II Exército não apenas confirma a infiltração comunista nas massas estudantis, como a interpreta como um desafio ao qual promete responder com a máxima violência. No mesmo sentido, a PM afirma que irá endurecer devido à morte de seu soldado (CM, 22/06/68, p.12. "Presidente soube de tudo pelo SNI"). Os estudantes, diante destas ameaças, garantem que não recuarão, respondendo a violência com a violência (JORNAL DA UEE, julho/68, p.2). 0 clima é de escalada.

Parte da grande imprensa, como é o caso do $C M$, toma partido nesta batalha, chegando até mesmo a desmentir declarações do governador carioca Negrão de Lima quando afirma que a PM está desarmada. 0 jornal em questão conta que seus jornalistas presenciaram inclusive os tiros dados pela mesma. Condena, assim, não apenas as violências praticadas pela polícia durante a sextafeira sangrenta, mas também 0 seu posterior incitamento à vingança contra os estudantes, a imprensa e os políticos (CM, 22/06/1968, p.12, "Negrão viu polícia desarmada").

Na determinação de vingança da PM e de caça às bruxas responsáveis pela subversão, os líderes estudantis figuram nos primeiros lugares da lista. Vladimir Palmeira, destacada liderança estudantil carioca, é acusado inclusive da morte do policial, sendo que pelo relato do $C M$ e dos estudantes fica explícito que o PM é morto por um objeto lançado do alto de um prédio (CM, 23/06/68, p.7 "Polícia vai caçar Vladimir e Dirceu em toda a cidade"). Aqui explicitamente, a questão da visibilidade propiciada pela imprensa: "todo mundo viu", comentam os estudantes. As autoridades militares enfatizam, no entanto, que uma vez 
eliminadas as lideranças comunistas, o ME perderá sua conotação política. Os estudantes discordam deste diagnóstico e asseguram que o ME apresenta um nível de conscientização coletiva independentemente de sua liderança (CM, 23/06/68, p.2, "Estudantes não recuam").

A linha dura sublinha, neste momento, a importância do estado de sítio inclusive para que a imprensa seja submetida à censura, pois contribui por meio da divulgação dos episódios do Rio para o alastramento do plano de subversão. 0 $C M$, em contrapartida, insiste que é o próprio governo, através de suas medidas repressivas, que está levando a população a aderir aos protestos estudantis (CASTELLO BRANC0, 1978, p.391).

No dia 26/06/1968, ocorre o protesto contra as violências policiais, que ficou conhecido como a Passeata dos Cem Mil. Há a adesão de vários setores populares: mães, artistas, professores, jornalistas, líderes cassados, servidores, populares, advogados, padres e freiras, dissidentes da "revolução" (integrantes da Frente Ampla). A violência está presente na retórica. Nos discursos, a derrubada da ditadura. Na prática, a PM mantém-se ausente. Não ocorrem ações violentas. 0 argumento do $C M$ parece confirmar-se: "a polícia é que gera a violência". 0 argumento de que a polícia apenas age em legítima defesa está ausente, pois sem a presença da polícia não há violência. Há, neste momento, um contraponto à Sexta-Feira Sangrenta. 0 governo e o ME sentem a necessidade de controlar a violência. Tanto a PM quanto a população são advertidas para não aceitar provocações. 0 recuo nas ações violentas faz parte da estratégia política dos dois grupos em questão: tentar atribuir o caráter violento para o inimigo na tentativa de conquistar o apoio da população.

0 CM divulga que as palavras de ordem não são mais restritas às reivindicações estudantis. Quanto aos discursos radicais feitos pelos estudantes durante a manifestação, afirma que, neste episódio, não incitaram à violência, sem, contudo, afastar a possibilidade de que possam instigá-la posteriormente. 0 fato de os estudantes revelarem publicamente suas propostas revolucionárias parece estar introduzindo novos dados à análise do $C M$, que passa a defender a postura de Vladimir Palmeira por sua serenidade, principalmente quando comparado com os líderes Elinor Brito e Luís Travassos, a seu ver mais radicais e violentos (CM, 25/06/68, p.2, "Líderes estudantis opinam").

Costa e Silva, oscilando mais uma vez entre atitudes repressivas e de liberalização, embora receba a Comissão dos Cem mil para o "diálogo" (ato 
surpreendente por partir de um presidente da República em plena ditadura militar), não cede a qualquer de seus reclamos. No jogo da negociação, os estudantes prometem voltar às ruas caso suas reivindicações não sejam atendidas. E cumprem, pois 50 mil pessoas participam da manifestação que visa mostrar que a proposta de "diálogo" do governo é finalmente desmascarada. Novamente, não há a presença da PM, mas as passeatas são terminantemente proibidas por Gama e Silva. Agora, a justificativa é dada pela retórica estudantil e pelo conteúdo de seus panfletos. 0 fato de o governo divulgar a apreensão de um documento da AP (Ação Popular) - que prega a tomada do poder pela violência -, no dia seguinte à passeata dos cem mil e do atentado ao II QG, revela a sua intenção de vincular o ME às atividades e propostas das organizações subversivas. A proibição das passeatas visa também a impedir a união dos políticos cassados da Frente Ampla, deputados e todos aqueles que estão na oposição ao governo engrossando as manifestações estudantis (MARTINS FILHO, 1995, p. 136-7).

Embora o Movimento Estudantil considere ter atingido importantes vitórias, há o início da confluência entre as denúncias do governo de um plano para a derrubada da ditadura por meio da violência e a explicitação das propostas revolucionárias estudantis.

Quando o CSN - Conselho de Segurança Nacional - se reúne (05/07/1968), torna-se mais explícito o acirramento da contradição entre o fechamento e a liberalização do regime, na medida em que as discussões giram em torno da tomada de medidas repressivas. 0 estado de sítio é mais uma vez descartado. Ao mesmo tempo, a proibição das passeatas e a promessa de sua repressão com a atuação decisiva das tropas federais são unanimemente reiteradas devido às ações ou planos de subversão. A imprensa está na mira do governo por ser considerada, agora, instrumento de desordem ao lado da agitação.

A revista Visão defende a luta estudantil apenas no que se refere às questões escolares, como a reforma universitária, mostrando a necessidade de sua inclusão no "diálogo" com o governo, embora questione, desde o início, a possibilidade de concretização do mesmo. Ao afirmar que a crise dos jovens é geracional, desautoriza-os a participar das questões políticas mais amplas como, no caso, a oposição ao regime. Apontando também para a característica comum dos movimentos estudantis brasileiros e dos demais países, pelo lado seu lado sombrio expresso nos cartazes, vem respaldar a possibilidade do plano internacional de subversão, tão caro ao governo. 
A cobertura dada pelo CM ao Movimento Estudantil é notável, não apenas relatando suas manifestações, divulgando a falas das lideranças e publicando na íntegra alguns de seus documentos e manifestos distribuídos à população, como também pelo fato de apresentar versão favorável ao mesmo. Já Visão dedica significativo espaço ao olhar governamental frente às agitações estudantis, demonstrando a coincidência de suas análises. A reunião do CSN repercute no posicionamento de Visão que, diferentemente do CM, não divulga as manifestações estudantis de junho na Guanabara, atendendo ao apelo do governo para que a imprensa não estimule a propagação da agitação - o silêncio que define uma fala. Com o acirrar dos acontecimentos, notamos a polarização da imprensa. Enquanto Visão concorda com o governo, atendendo aos seus apelos para que os protestos de rua não sejam divulgados, o CM, ao lado dos estudantes, continua marcando passo na sua veiculação.

\section{A Guerra da Maria AntôNia}

A imagem da guerra torna-se parte da rotina. 0 governo declara os estudantes o inimigo externo que precisa ser esmagado. Há novamente a promessa do estado de sítio caso continuem as passeatas - terminantemente proibidas em julho.

Os estudantes optam por entrar em recesso, evitando o confronto nas ruas, tão desigual neste momento, com as forças da repressão. A ordem agora é acumular forças e preparar $030^{\circ}$ Congresso da UNE. Algumas faculdades são ocupadas militarmente pelos mesmos, destacando-se a Faculdade de Filosofia da USP sediada na Rua Maria Antônia. No início de outubro (02/10/68), o CCC (Comando de Caça aos Comunistas), alojado no prédio do Mackenzie - situado na mesma rua - invade a faculdade de Filosofia, quando os estudantes estão fazendo pedágio para o $30^{\circ}$ Congresso da UNE. Com o revide dos estudantes da Filo-USP, há dois dias de "luta armada". A PM, agindo conjuntamente com o CCC, garante a superioridade bélica do Mackenzie. Um estudante é assassinado. A Faculdade de Filosofia é totalmente destruída (LOSCHIAVO DOS SANTOS, 1988, p. 226-7).

O CM denuncia a atitude provocativa do CCC nos conflitos da Maria Antônia. Já os jornais Folha de S. Paulo e O Estado de S. Paulo, embora concordando com este jornal carioca em relação ao fato dos conflitos da Rua Maria Antônia atingirem a dimensão de uma guerrilha urbana, atribuem ênfases distintas aos desencadeadores da violência. Os jornais paulistas em questão condenam a 
"guerra entre estudantes" que, segundo o seu relato, é provocada por tentativas de invasão ao prédio do Mackenzie pelos estudantes da USP. Afirmam, por outro lado, que o papel da guarda-civil no Mackenzie - cuja presença é solicitada por sua reitora - é proteger o prédio dos ataques dos alunos da Filosofia. Em nenhum momento estes jornais confirmam a presença de infiltradores do CCC ou a conivência da polícia. Apenas se referem a elas quando mencionam a versão dos estudantes. E, mesmo publicando relatos de testemunhas que descrevem os ataques dos policiais, logo apresentam depoimentos que elogiam a sua ação frente à violência dos baderneiros ( $F S P, 04 / 10 / 68$, p.12, "Testemunhas dão sua versão sobre os incidentes de ontem entre os estudantes da Maria Antônia"). Os dois jornais paulistas, além de apresentar versão desfavorável aos alunos da FiloUSP, enfatizam a violência por eles utilizada (FREI BETTO apud LOSCHIAVO DOS SANTOS, p.142).

A divulgação da "guerra da Maria Antônia" pelos órgãos da imprensa paulista revela um olhar bastante diferenciado da luta estudantil. A busca dos culpados pela violência é feita entre os próprios estudantes e não entre a polícia e 0 ME. Este enfoque repercute desfavoravelmente ao movimento como um todo, pois a violência é divulgada como sendo desencadeada e utilizada pelos estudantes, enquanto a polícia exerce o papel de proteção e, portanto, de manutenção da ordem.

A presença da polícia, para os jornais em questão, além de não gerar a violência, põe fim àquela desencadeada pelos estudantes. Podemos analisar esta perspectiva como um avanço na construção do inimigo externo pelo governo, na medida em que a imagem divulgada pela grande imprensa é a da violência estudantil, controlada pela ação da polícia que desarticula o conspirador. A destruição do prédio da Filosofia da USP na Maria Antônia pela PM simboliza, desta forma, a vitória da nova política repressiva que tem por alvo as universidades, pois delas fazem parte estudantes e intelectuais catalogados pelo governo como vanguarda revolucionária a ser banida.

No primeiro semestre, a presença da polícia é associada à deflagração de conflitos e, portanto, da violência, tanto pelo $C M$ - que está ao lado dos estudantes - quanto por Visão - que apresenta argumentação favorável ao governo. 0 CM continua criticando a ação policial na "guerra da Maria Antônia" (CM, 03/10/68, p.1, "Estudantes lutam nas ruas de São Paulo"). Em contrapartida, o governador Abreu Sodré, que permite uma passeata estudantil durante o episódio da morte de Edson Luís, impedindo o comparecimento da polícia, aciona, agora, o 
aparato repressivo dizendo que não permitirá a ação de comunistas sob qualquer hipótese.

A revista Veja, ao mostrar a composição dos dois grupos em choque, um deles formado por elementos da direita radical - CCC, FAC (Frente Anticomunista) e MAC (Movimento Anticomunista) -, e o outro por elementos esquerdistas pertencentes à "ex-UNE" - permite-nos inserir o episódio da Maria Antônia na conjuntura política mais ampla caracterizada por grupos extremistas de esquerda e de direita. Veja tece, então, fortes críticas às consequiências atingidas pela briga dos estudantes. Tanto assim que questiona o tempo todo o protesto dos estudantes da Filosofia contra a morte de seu colega no episódio da Maria Antônia, pois segundo o seu registro os próprios estudantes são culpados pela mesma (VEJA, 09/10/68, p.16, "Destruição e morte. Por quê?").

Podemos demarcar aqui uma significativa diferença em relação à morte de Edson Luís no primeiro semestre. Em torno de seu assassinato não restam dúvidas quanto à autoria da PM. Expressiva parte da população, carioca, indignada acompanha o seu enterro. 0 que não ocorre no sepultamento de José Guimarães, que é antecipado e acompanhado apenas por sua família e pela polícia. Na passeata em protesto contra a morte de José Guimarães, os estudantes queimam viaturas policiais e depredam o Citibank. A violência por eles praticada repercute, então, desfavoravelmente ao Movimento Estudantil. A adesão de setores da população às suas manifestação não são mais os mesmos. A FSP narra a oscilação das pessoas que assistem à passeata dos estudantes, algumas aplaudindo, outras vaiando. José Guimarães, assim como Edson Luís, não é nenhuma liderança expressiva. Mas, enquanto o primeiro é assassinado na hora do almoço em um restaurante universitário, onde inclusive trabalha, José Guimarães morre no momento em que recolhe pedras para ajudar os estudantes da Filosofia.

Abreu Sodré, enfatizando a presença de minorias radicais entre os estudantes e atribuindo-lhes a responsabilidade pelas desordens, salienta a imagem negativa do Movimento Estudantil, ao mesmo tempo em que justifica a sua atitude em relação à ação policial para impedir um maior número de mortes em conseqüência da luta armada deflagrada pelos estudantes (FSP, 04/10/68, p.13, "Sodré diz que porá fim aos focos de agitações"). Os estudantes, por sua vez, apontam para a conivência do governador de São Paulo com o CCC nos ataques contra a faculdade de Filosofia da USP, bem como na morte de José Guimarães. Para eles, a existência de grupos paramilitares muito contribui para colocar a repressão à paisana, 
sem interferir na imagem democrática que as autoridades teimam em sustentar (VANGUARDA NO EXÍLIO, 18/10/68, p.4 -5, "o que a imprensa não contou”).

Apesar das diferentes versões sobre os conflitos da Maria Antônia, o fato de ser uma "guerrilha urbana", uma luta "armada" envolvendo estudantes, não pode ser negado. Na "guerra da Maria Antônia" notamos, então, a radicalização no uso da violência tanto por parte dos grupos para-militares e da polícia, quanto dos estudantes. A ocupação da Faculdade de Filosofia da USP pelos estudantes não pode ser desvinculada de sua opção pela violência. Embora os estudantes da USP não utilizem suas armas neste momento, a vinculação de suas ações às organizações da esquerda armada explicita a opção de parte do Movimento Estudantil pela militarização (CARDOSO apud LOSCHIAVO DOS SANTOS, 1988, p. 237).

Podemos, a partir destas análises, afirmar que a opção do Movimento Estudantil pelo uso da violência é, ao mesmo tempo, resposta ao aumento ostensivo da repressão como também parte da opção política de algumas lideranças neste momento: a ocupação militar das faculdades. A conjuntura política mais geral de radicalização dos grupospara-militarese, portanto, adinâmicados acontecimentos, propicia a emergência de ações violentas - como, por exemplo, a defesa militar do prédio da filosofia da USP com formação de barricadas e revide aos ataques do Mackenzie, a prisão de dois membros do CCC e o debate em torno da formação de milícias estudantis - por estudantes que se identificam com as propostas da esquerda (RIDENTI, 1993, p. 48-9). Enquanto no primeiro semestre o Movimento Estudantil traz para as manifestações públicas as discussões da esquerda em torno da utilização da violência, no segundo semestre é o episódio da Maria Antônia que leva às ruas práticas de luta "armada".

Há, neste sentido, uma significativa mudança também na posição política adotada pelas lideranças do movimento. No primeiro semestre a imprensa considera Vladimir Palmeira um moderado e Luís Travassos um radical. Na "guerra da Maria Antônia”, José Dirceu - da linha de Palmeira - é apontado como o coordenador de todos os ataques da Filosofia pela imprensa paulista consultada e Travassos como aquele que, no final dos conflitos, tenta evitar o massacre dos estudantes, pedindolhes que desocupem o prédio.

Fazendo um contraponto com as manifestações do primeiro semestre, voltamos a constatar a centralidade da questão da violência na dinâmica dos acontecimentos de 68. Na Sexta-Feira Sangrenta, os estudantes são absolvidos pelo 
$C M$ da acusação de praticar atos violentos, atribuídos à polícia e aos populares. Na passeata dos cem mil, em repúdio à semana sangrenta, onde a violência está presente apenas na retórica, a adesão da população carioca é histórica. Já na guerra da Maria Antônia, a utilização da violência pelos estudantes contribui para denegrir a imagem do ME. Neste momento, a massa fica silenciosa.

Mesmo o $C M$, que vinha tecendo severas críticas às ações terroristas dos grupos de direita - dentre eles o CCC - e à invasão policial às diversas faculdades do país, passa a condenar qualquer manifestação de rua pelos estudantes. Desta forma, embora condene a invasão do CCC à Faculdade de Filosofia da USP, posicionando-se favoravelmente aos seus alunos, repudia também os atos violentos por eles praticados durante a passeata em protesto contra a morte de José Guimarães. A partir do momento em que o governo proíbe as passeatas advertindo que quaisquer delas serão fortemente reprimidas, este jornal passa a fazer um apelo aos jovens para que não sirvam de pretexto para sortidas totalitárias.

\section{O 30 CONGRESSO dA UNE}

Acompanhamos desde a "guerra da Maria Antônia" a presença da concepção militarista do Movimento Estudantil defendida principalmente pela União Estadual dos Estudantes de São Paulo - UEE-SP -, entidade responsável também pela organização do $30^{\circ}$ Congresso da UNE (11/10/68) que, "clandestino", é interditado em sua fase inicial no sítio Murundu, pertencente ao município de Ibiúna - cidade muito pequena do interior de São Paulo.

E será exatamente em torno da militarização do ME, explicitada pela presença de armas entre os estudantes em Ibiúna, que a imprensa paulista consultada e as autoridades militares centralizarão suas análises. Embora a quantidade de armas descrita pelo Jornal da Tarde não seja tão expressiva numericamente, vários artigos reiteram a sua presença em Ibiúna. JT divulga também diversos depoimentos de moradores desta cidade que não apenas descrevem homens armados, como também apontam para a vinculação do ME com os assaltos a bancos e para a semelhança dos estudantes com guerrilheiros (JORNAL DA TARDE, 14/10/68, p.28, "Por uma semana, Ibiúna teve medo").

Notamos então o respaldo dado pelo $J T$ às autoridades militares envolvidas com a apuração do $30^{\circ}$ Congresso da UNE. A prisão dos estudantes é pautada na inconstitucionalidade da reunião de uma entidade ilegal na que há a presença 
de armas. Tanto assim que a primeira atitude dos policiais a partir da prisão dos estudantes é revistá-los, buscando apoiar-se na Constituição e nos decretoslei para reprimir. 0 jornal divulga também a apreensão de material subversivo, tanto documentos vindos de Cuba como os que pregam a utilização da violência para a tomada do poder, esclarecendo, assim, a intenção da utilização das armas. Assim como todos os órgãos da grande imprensa consultados, o CM ressalta a ausência de violência da polícia durante o cerco à Ibiúna e a não-resistência dos estudantes ao mesmo (CM, 13/10/68, última página, "Presos todos líderes estudantis"). É importante deixar claro que a ausência de violência significa aí o não-derramamento de sangue. 0 JT descreve, em seguida, a cordialidade entre policiais e estudantes, apontando para o despreparo destes últimos tanto em relação à organização do Congresso quanto para atividades guerrilheiras. Por meio da publicação das piadas feitas pela polícia em relação aos estudantes, veicula uma imagem que os ridiculariza (JORNAL DA TARDE, 14/10/68, p. 23, "Prisão, o fim do Congresso"). Por sua vez, o CM confirma o forte aparato repressivo montado para a batida fulminante, fazendo menção, ao mesmo tempo, ao fato de que toda a liderança estudantil oposicionista ao atual regime é presa, sem resistência, apesar de ter organizado seu esquema de segurança conforme a técnica das passeatas. As autoridades responsáveis pelas prisões se vangloriam de tamanho feito: prender todos de uma vez sem derramamento de sangue. Os perigosos líderes, como os denomina Veja, os subversivos, que em seu discurso Abreu Sodré iguala aos terroristas, há tanto tempo procurados, finalmente, autuados em flagrante e com prisão preventiva, passarão um bom tempo na cadeia. Agora os moradores de Ibiúna podem dormir sossegados, pois a polícia volta a atuar em nome da ordem.

Todos os órgãos de imprensa consultados divulgam que está declarada a "guerra aos extremismos", sendo que em um dos pólos inserem o Movimento Estudantil. A derrubada do governo passa a ser 0 alvo de terroristas de esquerda e de direita, causando intranqüilidade para a sociedade e colocando em risco a presidência de Costa e Silva. As últimas manifestações estudantis coincidem com a onda crescente de atentados que dissemina um clima de terror.

Veja traz um questionamento expressivo do clima gerado pelas ações terroristas, qual seja, a indefinição de seus autores bem como das suas pretensões (VEJA, 16/10/68, p.15, "Todos presos - assim acabou o Congresso da ex-UNE"). Visão, mantendo sua postura de não dar cobertura aos episódios estudantis, deixa de relatar os fatos relacionados tanto à "guerra da Maria Antônia" como ao 
Congresso de Ibiúna em suas especificidades. Contudo noticia o quadro político mais geral, qual seja, a emergência natural da violência de direita em nome da ordem para conter a agitação contra o regime (VISÃO, 25/10/68, p.21, "Agora a violência vem da direita”). Há, portanto, segundo Visão, a radicalização da política quer pela esquerda quer pela direita. No entanto, a violência de esquerda, por apresentar claras conotações de luta de classes, é um perigo a todos. Neste caso, o governo está melhor preparado para enfrentá-la, conseguindo unidade interna para a sua repressão. A revista explicita, assim, sua postura contrária aos movimentos de oposição que ameaçam a integridade da sociedade, agindo como seu inimigo externo. Já a violência de direita, segundo sua perspectiva, ataca apenas a liderança presidencial e não o governo revolucionário como um todo, o que dificulta a ação repressiva do Estado frente a este segundo tipo de violência. Apesar de explicar o surgimento da violência de direita para o restabelecimento da ordem - não conseguido até então pelo presidente da República -, Visão defende a necessidade de sua supressão para que o governo não perca sua autoridade ao reprimir o movimento de esquerda. Por suavez, a revista Veja acredita na capacidade de Costa e Silva para mediar a guerra dos extremismos. Em contrapartida, o CM responsabiliza a repressão pela emergência dos radicais de esquerda e de direita, tecendo severas críticas ao governo que, calcado na força e na impunidade, suscita os extremismos.

A partir deste contexto podemos entender melhor a postura do $C M$ para quem o tratamento repressivo do governo, desde o início das manifestações estudantis, acaba levando à radicalização do $\mathrm{ME}$ e ao terrorismo. A mudança qualitativa do Movimento Estudantil - no contexto da eclosão dos extremismos - passa a ser veiculada por este jornal, que também contribui para a divulgação da sua imagem esquerdista, inclusive passando a admitir a presença de agentes infiltrados no interior do mesmo. Tanto assim que é distinta sua ênfase ao avaliar o Congresso de Ibiúna de acordo com a dinâmica dos episódios. Quando os estudantes são presos, defende a reunião da UNE, segundo ele, realizada clandestinamente graças à sua proibição pelo governo. No momento em que a sede da UNE é invadida na Guanabara, diz que os estudantes estão pondo lenha na fogueira e abrindo espaço para a tomada de medidas repressivas mais drásticas. Aí, então, faz referência à imaturidade dos mesmos na organização do Congresso. Quando a PM volta a reprimir as manifestações estudantis cariocas, causando a morte de mais um estudante e dois trabalhadores, o jornal em questão volta a defender os estudantes - responsáveis apenas por protestar contra a prisão de seus 
colegas em uma reunião legítima -, condenando a guerrilha da polícia, que mata dizendo estar defendendo a ordem.

A mudança na veiculação da imagem do Movimento Estudantil pelo $C M$ merece destaque nesta análise. Ainda que com diferentes ênfases em relação aos demais órgãos de imprensa consultados, deve-se levar em conta o fato de que passa a tratar parte dos estudantes como radicais e extremistas ao inserir suas manifestações no contexto da guerra entre o radicalismo de esquerda e de direita. 0 que podemos notar, até mesmo pela sua divulgação de artigos sobre o ME e o terrorismo na mesma página (CM, 18/10/68, última página). Não podemos deixar de registrar que este jornal tende a responsabilizar mais os radicais de direita pelos atos terroristas, afirmando que os mesmos visam a atribuir a culpa à esquerda - a conhecida tática da criação de fatos políticos. 0 JT apenas divulga discursos de autoridades militares que não apenas incriminam a esquerda por estas ações como as relacionam diretamente ao Congresso de Ibiúna. Segundo esta última versão, o objetivo dos terroristas é a implantação de um regime de força no Brasil.

No entanto, como o clima é de impunidade e indefinição das autorias dos atos terroristas, podemos afirmar que os dois jornais em questão contribuem para veicular a "imagem militarista" dos estudantes. A imagem do inimigo externo que, desde o início, faz parte do discurso do governo, torna-se, agora, dominante. Durante a cobertura do Congresso de Ibiúna e dos episódios estudantis imediatamente posteriores, a grande imprensa consultada, inclusive o $C M$, também reserva um espaço maior às declarações das autoridades militares e governamentais do que a depoimentos estudantis, fato que contribui para ressaltar a versão do governo.

Também neste sentido, a revista Veja veicula apenas os depoimentos de políticos que afirmam a necessidade de isolar a liderança ideológica do restante dos estudantes. Assumindo uma postura favorável ao governo - de forma até mesmo mais explícita que o JT -, condena radicalmente a oposição do Movimento Estudantil. Assim, ressalta tanto a importância das medidas tomadas por Costa e Silva frente às reivindicações estudantis - no caso, o relatório Meira Mattos e a reforma universitária - como as suas ações repressivas - a prisão das perigosas lideranças. Os governadores Abreu Sodré e Negrão de Lima também fazem coro, agora, às autoridades militares contra os subversivos, que merecem o mesmo tratamento dispensado aos terroristas, pois suas ações evidenciam a articulação do ME com os demais países. 
Há o canto da vitória do governo que acredita que, a partir de Ibiúna, o ME está liquidado politicamente e que os estudantes voltarão para as suas atividades normais. Veja e a FSP fazem eco ao governo afirmando que o ME está se recolhendo às suas bases e voltando a centrar suas preocupações nas questões escolares relativas ao final do semestre letivo. Costa e Silva, ao se referir às minorias radicais, insiste em não ser o presidente de um certo número de brasileiros, mas sim de todos os brasileiros. 0 discurso governamental, que tanto enfatiza a presença do inimigo externo e, portanto, da necessidade de despolitizar o Movimento Estudantil por meio da prisão de seus perigosos líderes, contamina todos os órgãos de imprensa consultados, apesar da maior ou menor ênfase apresentada por cada um deles. No mesmo movimento, a imprensa respalda a versão do governo, repercutindo no posicionamento oscilatório da população. Encontramos, aí, um dos elementos que permitem analisar sua ausência nos últimos episódios. No primeiro semestre, parte significativa da população do Rio e de São Paulo participa das manifestações de rua contra a repressão. No final de agosto, ainda notamos a mobilização de setores da sociedade devido à invasão de Brasília. Na "guerra da Maria Antônia" e depois da queda do Congresso de Ibiúna, os estudantes estarão isolados em suas manifestações apesar do aumento da repressão e, talvez contraditoriamente, também por isto (VALLE, 1999, p. 244).

A repressão, que no primeiro semestre aglutina a população contra 0 governo, agora, se não conta com o apoio da mesma, não recebe mais a sua contestação. A expressiva mobilização das mães tanto no Rio quanto em São Paulo contribui para acelerar a libertação dos estudantes presos em Ibiúna, mas como um movimento por uma causa específica: seus filhos. 0 comparecimento da massa às manifestações contra a ditadura vinha esvaindo-se desde a "guerra da Maria Antônia". Os estudantes indefesos passam a ser vistos como perigosos líderes, subversivos, engrossando o radicalismo de esquerda. A insegurança e o clima de pânico, gerados pela indefinição da autoria dos atentados terroristas e dos assaltos a bancos, levam a imprensa a veicular que a população está acuada, suspeitando de todos.

As organizações paramilitares muito contribuem também para mascarar o envolvimento do governo com ações terroristas e para criar a necessidade de fechamento do regime. No caso das ações terroristas contra o Movimento Estudantil, como explosões de bombas em faculdades, ameaça de extermínio aos estudantes comunistas, o CCC desempenhará um ativo papel, bastante enfatizado pela grande imprensa. 0 JT publica uma carta-aberta do CCC sem qualquer crítica, 
introduzindo-a apenas chamando atenção para o seu conteúdo. A imprensa dá visibilidade aos grupos paramilitares, que expõem sem qualquer escrúpulo as suas intenções, inclusive, ameaçando de morte Abreu Sodré, quando este determina a libertação da maior parte dos presos em Ibiúna. Este fato contribui para isentar de responsabilidade os agentes do DOPS e as autoridades do alto escalão militar - assim como a polícia no episódio da Maria Antônia -, sendo que estão atuando conjuntamente com o CCC. 0 Governo acelera as medidas para aprovar a reforma universitária através do Congresso, buscando ressaltar a sua disposição em atender aos anseios dos verdadeiros estudantes, dando também margem para que seja deslocada a atenção apenas para as ações terroristas das organizações paramilitares contra aqueles considerados subversivos, embora há muito tempo as autoridades militares estejam à sua procura.

A opção do Movimento Estudantil pela violência, em uma conjuntura de "guerra" entre os radicais de direita e esquerda, repercute na grande imprensa que veicula a imagem militarista dos estudantes (MARTINS FILHO, 1987, p.171-201). A população está ausente nas manifestações estudantis. 0 ME que tanto lutou para isolar a ditadura dos demais setores da sociedade, sofre, agora, não apenas o isolamento em relação ao restante da população, mas também a separação das lideranças de suas bases. No primeiro semestre, o ME desmascara o caráter violento da ditadura, atraindo a população. Agora, o governo e a veiculação de seu discurso pela imprensa desmascaram o caráter violento do ME. Desde junho, o governo estava vinculando a apreensão dos panfletos de esquerda às manifestações estudantis. Os documentos do $30^{\circ}$ Congresso confirmam a divulgação do $J T$ da proposta da utilização daviolênciapara a tomadado poder. Há, então, a coincidência entre as acusações governamentais e as bandeiras de luta estudantis. A população não está mais presente para a utilização da violência revolucionária necessária à derrubada do sistema capitalista. As práticas revolucionárias levadas às ruas pelas duas principais tendências do Movimento Estudantil estão duramente golpeadas. 0 $\mathrm{ME}$, enquanto movimento de massas, está fora do processo revolucionário. Aqueles que pretendem prosseguir deverão trilhar outros caminhos, como a alternativa de se integrarem à luta armada.

\section{Considerações FinaIs}

0 ano de 68 não acaba em outubro. Para a linha dura, não é suficiente a destruição do sonho revolucionário dos estudantes. É preciso exorcizá-lo, 
assim como o de todos aqueles que, aos seus olhos, apresentam os atributos de um inimigo externo. Apenas assistimos ao prenúncio da violência da ditadura, antecipando as práticas que farão parte do cotidiano com maior freqüência e crueldade. Se o inimigo já está isolado politicamente, trata-se, agora, de selar a vitória pelo extermínio da vanguarda revolucionária. Em dezembro, o AI-5 é finalmente decretado.

As manifestações de rua, estreitamente vinculadas pela linha dura à necessidade de fechamento do regime, antecipam a discussão sobre a possibilidade de novo ato institucional, como revelam os alvos privilegiados pelo mesmo. A imprensa e o ME, estarão no topo da lista. Os jornais e revistas consultados que, durante os últimos episódios de 68 , tanto clamavam pela tomada de atitude de Costa e Silva, recebem agora a sua resposta. No dia da decretação do AI-5, o CM que lutou até o fim pelas instituições democráticas, ao lado do Congresso Nacional - e até mesmo o JT, são violentamente invadidos e censurados.

No desenrolar dos acontecimentos de 68, o "diálogo é a violência". Seus atores centrais - a imprensa, o governo e o Movimento Estudantil - se posicionam por meio da dinâmica do combate entre a "violência revolucionária" e a "violência da ditadura". Os estudantes como "vanguarda provisória" fazem renascer, "nas ruas", o sonho da revolução (VAN DER WEID, 1968, p. 22). A inusitada presença da população em suas manifestações, no início, parece confirmar a disposição das "massas" para concretizá-lo. No entanto, a grande imprensa passará a condenar enfaticamente a subversão e a população estará ausente nos seus últimos embates. No confronto com a ditadura, o movimento de protesto acaba sendo relegado ao isolamento social.

\section{REFERÊNCIAS}

CARDOSO, Irene de Arruda Ribeiro. Os acontecimentos de 1968. Notas para uma interpretação. In: LOSCHIAVO DOS SANTOS, Maria Cecília (org.). Maria Antônia uma rua na Contramão. São Paulo: Nobel, 1988.

CASTELLO BRANCO, Carlos. Os Militares no Poder, vol. II - O Ato 5, Rio de Janeiro: Nova Fronteira, 1978.

COELHO, Cláudio Novaes Pinto. A Transformação Social em Questão: as práticas sociais alternativas durante o regime militar. Tese. (Doutorado em Sociologia) 
- Departamento de Sociologia, Universidade de São Paulo: São Paulo, 1990.

LOSCHIAVO DOS SANTOS, Maria Cecília (org.). Maria Antônia uma rua na Contramão. São Paulo: Nobel, 1988.

MARTINS FILHO, João Roberto. Movimento Estudantil e Ditadura Militar: 19641968. Campinas: Papirus, 1987.

. O Palácio e a Casern: A dinâmica Militar das Crises Políticas na Ditadura (1964-1969). São Carlos: Editora da UFSCar, 1995.

RIDENTI, Marcelo. O Fantasma da Revolução Brasileira. São Paulo: Editora UNESP/ FAPESP, 1993.

SIRKIS, Alfredo. Os Carbonários: memórias da guerrilha perdida. São Paul: Global editora, 1980.

VALLE, Maria Ribeiro do. 1968 - O Diálogo é a Violência: movimento estudantil e ditadura militar no Brasil. Campinas: Editora da Unicamp, 1999.

VAN DER WEID, Jean Marc. "O movimento estudantil e a luta popular. $30^{\circ}$ Congresso da UNE, 1968, mimeo.

VENTURA, Zuenir. 1968 - OAno Que Não Terminou: a aventura de uma geração. Rio de Janeiro: Círculo do Livro, 1988.

\section{Periódicos}

Correio da Manhã, Rio de Janeiro, 1968.

Folha de S. Paulo, 1968.

Jornal da Tarde, São Paulo, 1968.

Veja, São Paulo, 1968.

Visão, Rio de Janeiro, 1968.

\section{Periódicos Estudantis}

Jornal da UEE, 1968.

O Metropolitano, órgão oficial da UME (União Metropolitana de Estudantes), Rio de Janeiro,1968.

Vanguarda no Exilio - Informe do Centro Acadêmico "Visconde de Cairu", 1968. 